\title{
Protocol for visits of patients' pets in palliative care in a hospital
}

\author{
Protocolo para visita do animal de estimação do paciente \\ em cuidados paliativos em um hospital
}

Protocolo para la visita de mascotas de pacientes en cuidados paliativos en un hospital

\section{Tiago Oliveira Teixeiraa Gislene Pontaltia Helen Vargas Laitano ${ }^{a}$ Lucia Miranda Monteiro dos Santos ${ }^{\mathrm{a}}$ André de Oliveira Lopes ${ }^{a}$ Juliana Petri Tavares ${ }^{b}$}

\section{How to cite this article:} Teixeira TO, Pontalti G, Laitano HV, Santos LMM, Lopes A0, Tavares JP. Protocol for visits of patients'sets in palliative care in a hospital. Rev Gaúcha Enferm. 2021;42:e20200086. doi: https://doi. org/10.1590/1983-1447.2021.20200086
Hospital de Clínicas de Porto Alegre (HCPA). Porto Alegre, Rio Grande do Sul, Brasil.

b Universidade Federal do Rio Grande do Sul (UFRGS), Escola de Enfermagem, Departamento Enfermagem Médico-Cirúrgica. Porto Alegre, Rio Grande do Sul, Brasil.

\section{ABSTRACT}

Objective: To report the experience of the multidisciplinary health team in the construction and implementation of the assistance protocol for pets visiting patients admitted to a palliative care unit.

Method: This is an experience report about the construction and implementation of a protocol in a university hospital in the South of Brazil by a working group from the multidisciplinary team of the Palliative Care Program and composed of three nurses, a physician, a psychologist, a social worker, a manager, and a nutritionist. The period of construction and implementation of the protocol was from September 2017 to April 2019.

Results: The construction of the protocol by the multidisciplinary team followed three stages: planning, execution, and implementation, which enabled the release of visits of patients' pets in palliative care.

Conclusion: The construction of the protocol allowed for the institutionalization of the visit of patients' pets in palliative care in a university hospital, bringing benefits to patients and their families.

Keywords: Palliative care. Complementary therapies. Bonding, human-pet. Patient care team. Protocols. Methodology.

\section{RESUMO}

Objetivo: Relatar a experiência da equipe multiprofissional em saúde na construção e implantação do protocolo assistencial para visita dos animais de estimação dos pacientes internados em uma Unidade de Cuidados Paliativos.

Método: Trata-se de um relato de experiência de uma ação realizada em um hospital universitário do sul do Brasil por um grupo de trabalho originado da equipe multiprofissional do Programa de Cuidados Paliativos, composto por três enfermeiros, um médico, um psicólogo, um assistente social, um administrador e uma nutricionista. 0 período de construção e implementação do protocolo foi de setembro de 2017 a abril de 2019

Resultados: A construção do protocolo pela equipe multiprofissional seguiu três etapas, planejamento, execução e implementação, e resultou na liberação para visita dos animais de estimação dos pacientes em cuidados paliativos.

Conclusão: A construção do protocolo permitiu a institucionalização da visita dos animais de estimação dos pacientes em cuidados paliativos em um hospital universitário, trazendo benefícios para os pacientes e seus familiares.

Palavras-chave: Cuidados paliativos. Terapias complementares. Vínculo homem-animal de estimação. Equipe de assistência ao paciente. Protocolos. Metodologia.

\section{RESUMEN}

Objetivo: Informar la experiencia del equipo de salud multiprofesional en la construcción e implementación de un protocolo de atención para visita de mascotas, para los pacientes internados en una unidad de cuidados paliativos.

Método: Se trata de un informe de experiencia sobre la construcción e implementación de un protocolo en un hospital universitario en el sur de Brasil, realizado por un grupo de trabajo originado a partir del equipo multidisciplinario del Programa de Cuidados Paliativos y compuesto por tres enfermeras, un médico, un psicólogo, un trabajador social, un administrador y un nutricionista. El período de construcción e implementación del protocolo abarca desde septiembre de 2017 hasta abril de 2019.

Resultados: La construcción del protocolo por la experiencia del equipo multiprofesional siguió tres etapas: planificación, ejecución e implementación, que permitieron la habilitación de las visitas de mascotas de pacientes en cuidados paliativos.

Conclusión: La construcción del protocolo permitió institucionalizar la visita de mascotas de pacientes en cuidados paliativos en un hospital universitario, brindando beneficios tanto a los pacientes como a sus familias.

Palabras clave: Cuidados paliativos. Terapias complementarias. Vínculo ser humano-animal. Grupo de atención al paciente. Protocolos. Metodología. 


\section{INTRODUCTION}

Palliative Care consists of multidisciplinary assistance aimed at promoting improvement of quality of life in patients who are facing a clinically incurable disease with fatal evolution, as well as their family members. This assistance is carried out by managing pain and by the prevention and relief of physical, psychic, social, and spiritual suffering ${ }^{(1-2)}$.

The work of a multidisciplinary palliative care team must be guided by clear principles that should be present when performing the activities. These principles of palliative care were published by the World Health Organization (WHO) in 1986 and restated in 2002, including: valuing life, considering death as a natural process; establishing care that does not shorten or prolong the arrival of death; and providing patients and their family members with support to relieve pain and other symptoms that cause suffering in the care strategy, so that the patients can live with quality as actively as they can in their remaining days ${ }^{(2)}$.

Accordingly, multidisciplinary activities encompass patients and their family, this being understood as an open system of human beings in mutual interaction over time whose changes are conditioned by the external environment. We can also include pets in families, according to the Brazilian legislation. This is a new family composition, named "multispecies", with a human-animal integration and an affective relationship ${ }^{(3-4)}$.

Pets are increasingly being included in the care activities as a way of therapeutic approach for patients in palliative care, providing benefits to their emotional and physical health ${ }^{(5-6)}$. Pain, suffering, and fatigue reduction is also evidenced, as they are considered family members and, therefore, their visit can represent an approximation of the home environment with the hospital setting ${ }^{(7-8)}$. However, there seems to be certain lack of high-quality literature in this area, as well as reports of the benefits of visits of patients' pets in palliative care ${ }^{(6)}$, ratifying the need for new studies on this theme.

Given the need for more studies and the desire of some patients admitted in the Palliative Care Inpatient Care Unit to receive visits of their pets, the need emerged to prepare, develop, and implement a release protocol to provide such opportunity.

A protocol is the description of a specific situation of assistance/care, which contains operational details and specifications about what to do, who does it and how it is done, so as to guide the professionals in the assistance decisions. Some institutions use protocols to organize their services, optimize their work, and standardize conducts, incorporating them to the assistance practice ${ }^{(9)}$.

In view of what was shown, this study aims at reporting the experience of the multidisciplinary health team in constructing and implementing the protocol of visits of inpatients' pets in a Palliative Care Unit in a university hospital.

\section{$\square$ METHOD}

This is an experience report on the construction and implementation of a care protocol to allow the visit of patients' pets in a Palliative Care Unit in a university hospital in the South of Brazil. The hospital has thirteen beds for adults and older adults in palliative care and counts on the assistance of a multidisciplinary team to provide care to the patients. The multidisciplinary team is composed of nine nurses, three physicians, two psychologists, one physiotherapist, one nutritionist, one pharmacist, one occupational therapist, one social worker, one physical educator, one manager, and one Medicine and Nursing professor, as well as support professionals: two guards and four receptionists.

This study reports the work that was started in September 2017 through a working group composed of professionals members of the Palliative Care Program of the Institution. The protocol was constructed and operationalized following three stages:

1. Planning: definition of the target population, organization of a work team, and search in the literature on the procedures that characterize the best therapeutic practices related to animals.

2. Execution: discussion with the multidisciplinary team in palliative care for necessary adjustments in the execution of the proposal and, after the necessary adjustments together with the palliative care service, preparation and definition of the the final proposal of the care protocol for the visits of patients' pets in palliative care.

3. Implementation: implementation of the protocol with the presentation of the process flowchart for better understanding, training of the executing team, and supervision of its use.

The implementation of the process took place in April 2019, with the first visit of a pet in the hospitalization unit. As this is an experience report of the construction and implementation of a protocol to allow the visit of patients' pets, the free and informed consent was not applied, since it did not involve a study with human beings. 


\section{EXPERIENCE REPORT}

The elaboration and implementation of the protocol were defined based on the literature ${ }^{(9)}$ and adapted according to the institutional standard.

\section{First stage: Planning}

The construction of the protocol was started by forming a working group composed of professionals from different areas, namely: three nurses, one physician, one psychologist, one social worker, one manager, and one nutritionist, with weekly meetings from September to December 2017. In these meetings, the scientific papers ${ }^{(3-11)}$ related to the main theme of the protocol were selected, and discussed, researched in national and international databases, in order to seek subsidies for the protocol preparation. The therapeutic practices related to animals in the hospital environment are diverse, so it was important to propose some definitions.

In this stage, some inclusion criteria for pets were also established, following the guidance of the Hospital Infection Control (Controle de Infecção Hospitalar, $\mathrm{ClH}$ ) and based on studies ${ }^{(6-7)}$ : healthy pets; with updated immunizations; bath and grooming in the last seven days; friendly behavior; with no history of aggressiveness with other animals or people; and that respond correctly to the commands of the companion/family member. Subsequently, the Acknowledgment and Responsibility Statement was prepared and defined (Figure 1). This is signed by the patient or the person responsible for them if there is the desire to receive the visit of the pet and the consent of the family members for enabling the process.

\section{Second stage: Execution}

The second stage was characterized by the performance of actions by the multidisciplinary health team to construct the logistics and structure of the assistance involved at the moment of the patient's pet visit in palliative care.

Regarding the performance of the multidisciplinary team, the actions took place through meetings at the work environment, discussing health care questions involved in the work process and aspects directed to the protocol proposed. Accordingly, during the meetings, the factors related to logistics and to the moment to address the patients about their pets were discussed. It was sought to identify the patients eligible for the protocol and to capture suggestions for improvements in the process. These actions enabled a knowledge exchange of the several professions involved, defining the creation of strategies to solve problems arising from the protocol.

Support areas, such as Hospital Infection Control, the Patient Care Administrative Service, Logistics, and Hospitality, were consulted to analyze the feasibility of the process stages in their domain. In order to enable the process, family members, guards, administrative reception assistants, and the multidisciplinary care team of the hospital's Palliative Care Institutional Program were also included.

Therefore, the protocol was gradually structured with the following implementation stages: execution place and period, executing team, materials, activities developed by the team, and expected results. The Clinical Hospitalization Unit of the Álvaro Alvim Unit adopted the flow as an institutional pilot, which was delimited to take place on Wednesdays from 2 p.m. to 8 p.m. For cases in which the patient is in an advanced terminal stage, the situation can be assessed and the visit can occur in a different period and in other conditions provided that it does not result in risks to the patient and the hospital in general. Also, at the visit time, the multidisciplinary team checks whether there is more than one patient hospitalized in the same room and then asks for authorization from the other patient and their family member.

In addition to the materials applied to customary processes, such as corporate access and control systems, specific materials related to the process logistics were also prepared, such as the "Visit of pets AAU" Checklist (Figure 2) and the Pet Badge (Figure 3).

The executing team was composed of the multidisciplinary assistance team of the hospital's Palliative Care Program, responsible for all the protocol stages, although supported by a guard and a receptionist at this stage. The activities were established for their execution according to the professional competences of each executing class, which are specified below.

It is responsibility of the multidisciplinary care team: to identify and assess the situation in which the visit of the inpatient's pet is applicable; to previously instruct the caregiver/family member and the patient with information regarding the Checklist for access to the Unit; to request from the caregiver/family member the filling and signature of two copies of the Acknowledgment and Responsibility Form (PCP), handing in one copy to the caregiver/family member; to perform the release by email, with the patient's medical record number and expected date for the visit of the 


\section{ACKNOWLEDGMENT AND RESPONSIBILITY STATEMENT (PCP)}

I, _ bearer of the Identity Card No. Individual Taxpayer Register (CPF) , caregiver/family member responsible for bringing the pet belonging to patient medical record No bed No. hospitalized in the Clinical

Hospitalization Unit of the Álvaro Alvim Unit, declare to be aware that:

\section{THE INCLUSION/EXCLUSION CRITERIA FOR THE VISIT OF THE PATIENT'S PET IN THE PALLIATIVE CARE CENTER ARE AS FOLLOWS:}

1.1. The pet must belong to the patient hospitalized in the Álvaro Alvim Unit of the Clinical Hospital of Porto Alegre;

1.2. The pet must be docile, accepting the presence of strangers and people in general;

1.3. The pet must meet the grooming and health criteria for visits, as well as being up to date with the mandatory vaccination schedule;

1.4. The entrance in the hospital environment of pets presenting signals of infection will not be allowed, such as fever, vomiting, diarrhea, skin wounds, eye or ear discharge, urinary or fecal incontinence, and cough, or animals under drug treatment until one week before the visit.

\section{THE FOLLOWING ARE ATTRIBUTIONS OF THE CAREGIVER/FAMILY MEMBER FOR THE VISIT OF A PET:}

2.1. Ensuring that the patient and the responsible team authorized the entrance of the pet;

2.2. Providing the pet a bath within 7 days before the visit;

2.3. Having intimacy with the pet in question and knowing the challenges that may be faced, such as surprising noises, different smells, and agglomeration of people;

2.4. Ensuring the use of an identity badge (name of the pet and bed number that it will visit) provided by the Reception of the Álvaro Alvim Unit for the pet.

2.5. Transporting the pet in an adequate pet travel carrier;

2.6. Not allowing the pet to be alone, keeping it always with its leash on throughout the entire visit in the patient's bed.

2.7. Not allowing the pet to go in areas not previously authorized.

2.8. Ensuring that the pet's physiological needs are met as much as possible before the visit;

2.9. Keeping the pet far from bandages, drains, venous accesses, etc.

\section{AREA RELEASED FOR VISITS:}

3.1. The pet must be inside the travel carrier throughout the entire route to the place scheduled for the visit; 3.2. The pet and its caregiver/family member will enter through the Central Entrance of the Álvaro Alvim Unit; 3.3. The pet and its caregiver/family member will access the Clinical Hospitalization Unit ( $3^{\text {rd }}$ floor) through the central elevator; 3.4. The visit of the pet will be allowed only at the inpatient's bed in the Clinical Hospitalization Unit;

3.5. Permanence of the pet in any other place of the hospital is prohibited;

3.6. Exceptional situations for the visit of the inpatient's pet shall be reported for assessment of the multidisciplinary team of the Palliative Care Program of the Clinical Hospital of Porto Alegre.

\section{DATE, TIMES AND FREQUENCY:}

4.1. The visits can be:

4.1.1. Weekly: Wednesdays, from 2 p.m. to 8 p.m., for all patients who request the visit of their pets according to the request and tolerance of the patient and the family;

4.1.2. Emergencies: on any other weekday, in special situations in which the patient is not in proper conditions to wait for the day devoted to visits (Wednesdays) due to physical or emotional conditions, or in other situations assessed by the multidisciplinary team of the Palliative Care Program.

Porto Alegre,

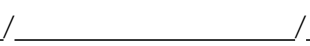

(Signature of the caregiver/family member of the patient who owns the pet)

(Employee responsible for delivering the Statement)

Figure 1 - Acknowledgment and Responsibility Statement Source: Prepared by the authors.

Note: ${ }^{*} \mathrm{PCP}=$ Palliative Care Program; $(\mathrm{PF}=$ Cadastro de Pessoas Físicas (Individual Taxpayer Register); $A A U$ = Álvaro Alvim Unit. 


\[ \begin{array}{c}\text { Checklist } \\
\text { Visit of Pets AAU }\end{array} \]
\begin{tabular}{|l|l|}
\hline Date: \\
\hline Patient's name/medical record: \\
\hline Name of the person responsible for the animal: \\
\hline Name of the pet: \\
\hline$\square$ & $\begin{array}{l}\text { Mandatory updated vaccination card for each pet, signed by a veterinarian registered with the regulatory } \\
\text { body for the profession. }\end{array}$ \\
\hline$\square$ & $\begin{array}{l}\text { Receipt provided by the clinic or pet shop, evidencing the pet's bath and grooming until } 7 \text { days before } \\
\text { the visit. }\end{array}$ \\
\hline & This Checklist must be filed. \\
\hline
\end{tabular}

Figure $\mathbf{2}$ - Checklist model of the hospital for the visit of pets

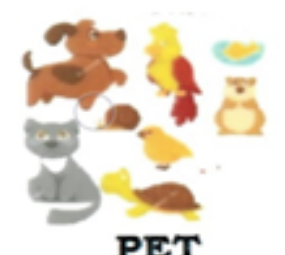

PET

Figure 3 - Pet Badge

Source: Prepared by the authors.

pet; and to ensure that hand hygiene always occurs when professionals, family members, and caregivers have direct contact with the pet.

Even with regularized protocols, attention must be paid mainly to patients with their immune system compromised or not fully developed, such as older adults, and those under immunosuppressive treatments, the latter being at greater risk of diseases associated with the pet. Therefore, the research studies suggest that hand hygiene after the contact with pets is an adequate activity, reducing the risk of infections and development of diseases ${ }^{(12)}$.

It is responsibility of the guard to check the email authorizing the pet access and the release of access of the person responsible and of the animal at the Hospital's Reception. The receptionist must forward the release by email to the
Security Service, with the patient's medical record number and expected date for the visit of the pet; receive the caregiver/family member and the pet at the Hospital's Central Reception; check, through the corporate system, the pet access authorization, previously carried out through email by the responsible multidisciplinary team; ensure that the pet meets the visit criteria by applying the Checklist, which will be filed in the Inpatient Unit for future reference; perform the identification of the caregiver/family member of the pet owner according to the established process; and provide the pet identification badge with the registration of its name and the bed of the patient to be visited.

It is also the receptionist role to review some guidelines with the caregiver/family member about the animal transportation in the hospital and its permanence during the visit. The pet must be taken in a travel carrier to the place scheduled for the visit, and access to the Inpatient Unit must be through the central elevator, going directly to the bed of the pet owner. The permanence of the pet with the patient at the bed will have a three-hour limit; the pet must be with its leash on during the entire visit at the patient's bed. When the visit ends, the pet must be taken in a travel carrier by the caregiver/family member to the Hospital's Reception and its identification badge will be returned.

With preparation of this protocol, it is expected to improve the quality of life of the inpatients, reducing their anxiety and sadness, as well as longing for their pet, so as to promote enrichment of their routine and to cheer up their life through the interaction between the pet and its owner. 


\section{Third stage: Implementation}

First, the implementation of the protocol took place through a multidisciplinary meeting with the multidisciplinary care team of the hospital's Palliative Care Program, responsible for all the protocol stages, beyond the guard and receptionist, involved in the pet visit process. The protocol final version and the flows where the visits would occur were presented.

The protocol validation occurred through a simulated event, in which an empty travel carrier was used. It was sought to follow the routes to be traveled, since the arrival at the unit, going through the document verification, the Checklist filling, and the pet badge delivery, until the transportation to the patient's bed, observing the necessary time for all the process. All steps described in the protocol were followed as to experience, even in a simulated way, how the visit would be. A new meeting was arranged by the multidisciplinary team to adequate the flow and define the final flowchart (Figure 4).

Later, the protocol was reviewed by the hospital's Nursing Education Service team, the executing team was trained through a face-to-face meet addressing the protocol developed, and the nurses were supervised by physicians during the first visits. Therefore, it was possible to make this therapeutic approach available to patients and family members with quality and safety.

With this experience, incidents or problems related to the pets were not registered, such as bites or behavior changes of the pet and questioning or disapproval of other patients and family members. Instead, it was observed moments of joy and affection experienced by the patient and their family members when meeting the pet, feelings that also affected all the team, which also interacts affectively with the pet.

Human beings are inherently social; they need social relationships and emotional bonds. This need is not obligatorily restricted to relationships among human beings: it can cross the limit of species, enabling, therefore, the bond between human beings and animals ${ }^{(11)}$. Therefore, nurses are implementing interventions that reduce hospitalization stress and make the treatment easier; for this reason, the use of alternative therapies in the care, which are capable of promoting strategies to make it less traumatic, have been valued (13).

The pet visit has been established as an approach of leisure and distraction in a cycle of affective exchanges, which divert the focus on the disease and relieves the longing. It brings benefits in different dimensions, whether emotional, social, or physical, for patients and family members, being synchronized with the palliative care principles, such as humanized care, singularity, and quality of life promotion ${ }^{(2)}$.

In this regard, evidence point out the potential of interactions with pets, especially the own dog pet, to increase oxytocin levels in human beings. The effects of oxytocin may be triggered in response to single meetings with pets, but stable relationships with pets, such as adoption and continuous pet care are related to potent and enduring effects. Among these effects, it is possible to mention increased confidence, positive self-perception, and generosity, decreased depression and stress, increased pain threshold, among others ${ }^{(14)}$.

Therefore, it is possible to note that pet visits bring benefits for patients hospitalized in palliative care even though protocols are needed to regulate the entrance of pets The application of protocols enables the implementation of valid recommendations proposed by clinical guidelines in programs of care quality and effectiveness ${ }^{(15)}$.

By considering the outcomes of this report of interaction between patients and pets, it is sought to socialize this experience to encourage new projects that benefit people in palliative care and help further studies using this approach.

\section{a CONCLUSION}

Considering this scenario and aiming at improving the quality of care to patients in palliative care, this study aimed to describe the construction and implementation process of a care protocol for the visits of patients' pets in palliative care in a university hospital of Porto Alegre. This description intends to help other institutions to conduct and enable a safe visit of pets in the hospital environment through the experience report of the multidisciplinary team regarding this process.

The implementation of an institutional protocol for the visit of the patients' pets in palliative care in a university hospital enabled an improved comfort of the patients hospitalized, who could meet again their pets. Beyond that, the outcomes of this work contribute directly to the patients care and generate subsidies in health training and new studies.

The study limitations are both related to the lack of measurement regarding the real impact of the pet visit on the quality of life of the patient in palliative care and the lack of studies related to this specific theme for purposes of comparison. Therefore, it is suggested the development of new longitudinal and experimental studies aiming to follow the benefits of the visit of patients' pets in palliative care. 


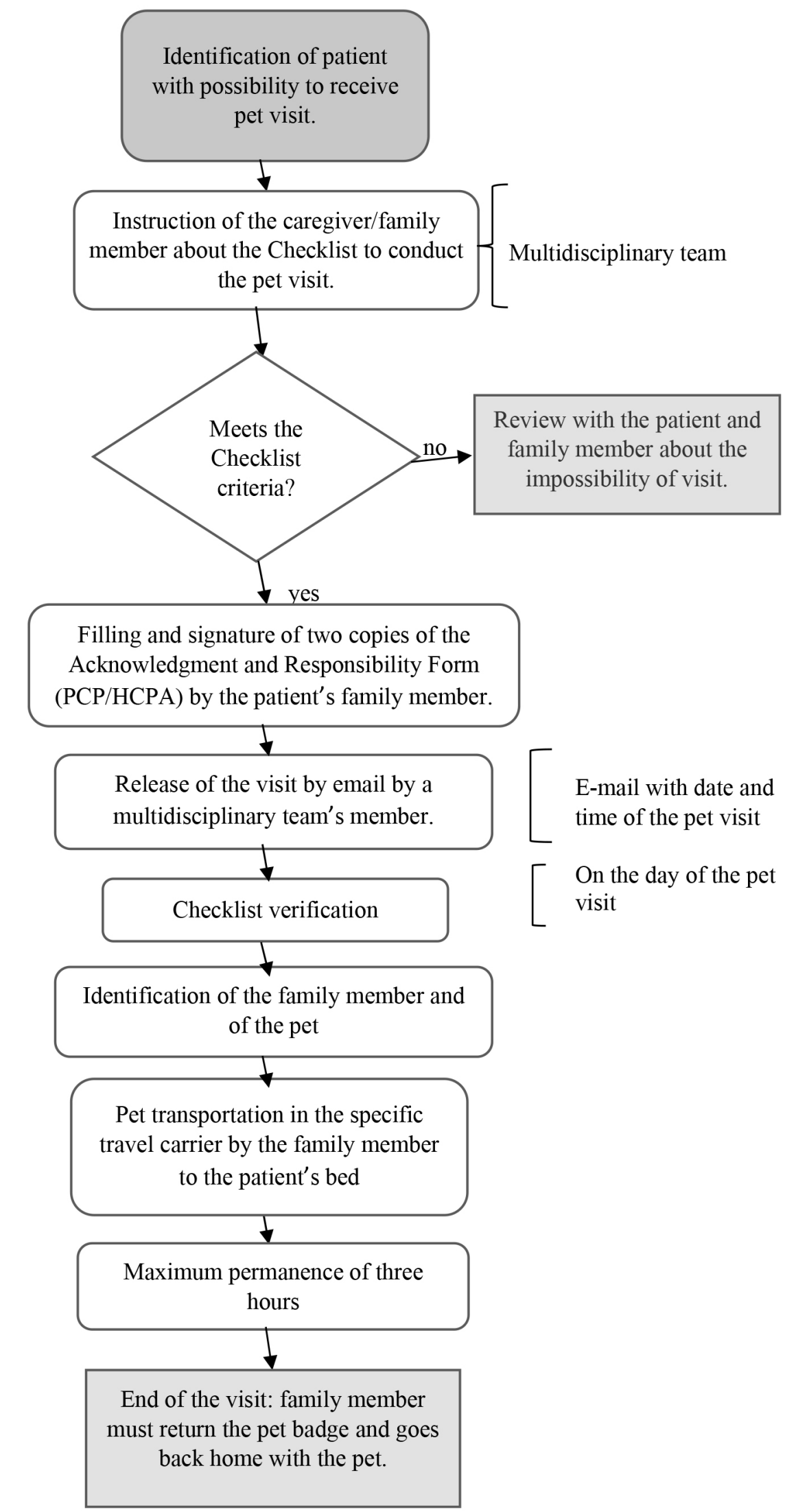

Figure 4 - Protocol for the visit of the patient's pet in palliative care: Final flow diagram Source: Prepared by the authors. 


\section{REFERENCES}

1. Organización Mundial de la Salud (CH). Cuidados paliativos. Geneva: OMS; 2007 [cited 2020 Jun 12]. Control del cáncer: aplicación de los conocimientos; guía de la OMS para desarrollar programas eficaces, módulo 5. Available from: https://apps.who.int/iris/bitstream/handle/10665/44025/9789243547343_spa. pdf; ;sessionid=20F1987ADD329CD25A11B2D813DB7DED? sequence=1

2. Carvalho RT, Parsons HA, organizadores. Manual de cuidados paliativos ANCP: ampliado e atualizado. 2a ed. Rio de Janeiro: ANCP; 2012 [cited 2020 Jun 12]. Available from: http://biblioteca.cofen.gov.br/wp-content/uploads/2017/05/ Manual-de-cuidados-paliativos-ANCP.pdf

3. Reigada C, Ribeiro JLP, Novellas A, Pereira JLP. 0 suporte à família em cuidados paliativos. Textos Contextos (Porto Alegre). 2014 [cited 2020 jun 12];13(1):159-69. Available from: https://revistaseletronicas.pucrs.br/ojs/index.php/fass/article/ view/16478/11761

4. Hodgson K, Barton L, Darling M, Antao V, Kim FA, Monavvari A. Pets' impact on your patients' health: leveraging benefits and mitigating risk. J Am Board Fam Med. 2015;28(4):526-53. doi: https://doi.org/10.3122/jabfm.2015.04.140254

5. Chan MM, Rico GT. The "pet effect" in cancer patients: risks and benefits of human-pet interaction. Crit Rev Oncol Hematol. 2019;143:56-61. doi: https:// doi.org/10.1016/j.critrevonc.2019.08.004

6. MacDonald JM, Barrett, D. Companion animals and well-being in palliative care nursing: a literature review. J Clin Nurs. 2015;25(3-4):300-10. doi: https://doi. org/10.1111/jocn.13022

7. Krause-Parello CA, Levy C, Holman E, Kolassa J. Effects of VA facility dog on hospitalized veterans seen by a palliative care psychologist: an innovative approach to impacting stress indicators. Am J Hosp Palliat Care. 2018;35(1):5-14. doi: https://doi.org/10.1177/1049909116675571
8. Folch A, Torrente M, Heredia L, Vicens P. Effectiveness of dog-assisted therapy in the elderly: a preliminary study. Rev Esp Geriatr Gerontol. 2016;51(4):210-6. doi: https://doi.org/10.1016/j.regg.2015.12.001

9. Pimenta CAM, Pastana ICASS, Sichieri K, Solha RKT, SouzaW. Guia para construção de protocolos assistenciais de enfermagem. São Paulo (SP): COREN; 2015 [cited 2020 Jun 12]. Available from: https://portal.coren-sp.gov.br/sites/default/files/ Protocolo-web.pdf

10. Schmitz A, Beermann M, MacKenzie CR, FetzK, Schulz-Quach C. Animal-assisted therapy at a University Centre for Palliative Medicine - a qualitative content analysis of patient records. BMC Palliat Care. 2017;16(1):50. doi: https://doi.org/10.1186/ s12904-017-0230-Z

11. Santaniello A, Dicé F, Claudia Carratú R, Amato A, Fioretti A, Menna LF. Methodological and terminological issues in animal-assisted interventions: an umbrella review of systematic reviews. Animals (Basel). 2020;10(5):759. doi: https://doi.org/10.3390/ani10050759

12. Stull JW, Brophy J, Weese JS. Reducing the risk of pet-associated zoonotic infections. CMAJ. 2015;187(10):736-43. doi: https://doi.org/10.1503/cmaj.141020

13. Moreira RL, Gubert FA, Sabino LMM, Benevides JL, Tomé MABG, Martins $M C$, et al. Assisted therapy with dogs in pediatric oncology: relatives' and nurses' perceptions. Rev Bras Enferm. 2016;69(6):1122-8. doi: https://doi. org/10.1590/0034-7167-2016-0243

14. BeetzA, Uvnäs-Moberg K, Julius H, Kotrschal K. Psychosocial and psychophysiological effects of human-animal interactions: the possible role of oxytocin. Front Psychol. 2012;3:234. doi: https://doi.org/10.3389/fpsyg.2012.00234

15. Afonso TC, Bezerra ALQ, Brandão LGVA, Amaral RT, Teixeira CC, Souza ACS, et al. Implantação da Comissão da Qualidade e Segurança do Paciente em instituição hospitalar: relato de experiência. Rev Eletrôn Acervo Saúde, 2019;11(7):e618. doi: https://doi.org/10.25248/reas.e618.2019 


\section{- Authorship contribution:}

Conceptualization: Tiago Oliveira Teixeira, Juliana Petri Tavares, Helen Vargas Laitano.

Gislene Pontalti, André de Oliveira Lopes, Lucia Miranda Monteiro dos Santos.

Data curation: Tiago Oliveira Teixeira, André de Oliveira Lopes.

Formal analysis: Juliana Petri Tavares.

Investigation: Tiago Oliveira Teixeira, Juliana Petri

Tavares, Helen Vargas Laitano.

Gislene Pontalti, André de Oliveira Lopes, Lucia Miranda Monteiro dos Santos.

Methodology: Tiago Oliveira Teixeira, Juliana Petri

Tavares.

Project management:Tiago Oliveira Teixeira, Juliana Petri Tavares.

Supervision: Juliana Petri Tavares.

Validation: Tiago Oliveira Teixeira, Juliana Petri Tavares. Visualization: Tiago Oliveira Teixeira, Juliana Petr Tavares, Helen Vargas Laitano, Gislene Pontalti, André de Oliveira Lopes, Lucia Miranda Monteiro dos Santos. Writing - Original draft: Tiago Oliveira Teixeira, Juliana Petri Tavares, Helen Vargas Laitano, Gislene Pontalti, André de Oliveira Lopes, Lucia Miranda Monteiro dos Santos.

Writing - Review and editing: Tiago Oliveira Teixeira, Juliana Petri Tavares.

\section{- Corresponding author:}

Juliana Petri Tavares

Email: jupetritavares@gmail.com

\section{Associate editor:}

Carlise Rigon Dalla Nora 